\title{
Co-based soft magnetic bulk glassy alloys optimized for glass-forming ability and plasticity
}

\author{
LI LI ${ }^{1}$, HUAIJUN SUN ${ }^{2}, *$ YUNZHANG FANG ${ }^{2}$ and JIANLONG ZHENG ${ }^{2}$ \\ ${ }^{1}$ College of Xing Zhi, Zhejiang Normal University, Jinhua 321004, China \\ ${ }^{2}$ Key Laboratory of Solid State Optoelectronic Devices, Zhejiang Province, Zhejiang Normal University, \\ Jinhua 321004, China
}

MS received 12 August 2015; accepted 28 December 2015

\begin{abstract}
Co-based bulk glassy alloys (BGAs) have become more and more important because of their nearly zero magnetostriction and high giant magneto-impedance effect. Here, we report the improvement of glass-forming ability (GFA), soft-magnetic properties and plasticity by a small addition of Mo atoms in CoFeBSiNbMo BGAs. $\left(\mathrm{Co}_{0.6} \mathrm{Fe}_{0.4}\right)_{69} \mathrm{~B}_{20.8} \mathrm{Si}_{5.2} \mathrm{Nb}_{5-x} \mathrm{Mo}_{x}$ ferromagnetic BGA cylindrical glassy rods were fabricated successfully with a diameter of $5 \mathrm{~mm}$ by conventional copper mould casting method. It reveals that the substitution of a small amount of Mo for $\mathrm{Nb}$ makes the composition to approach a eutectic point and effectively enhances the GFA of alloy. In addition to high GFA and superhigh strength, the compressive test shows that the Mo addition can improve the plasticity for the obtained BGAs. The combination of high GFA, excellent soft-magnetic properties and good plasticity demonstrated in our alloys is promising for the future applications as functional materials.
\end{abstract}

Keywords. Co-based glassy alloys; glass-forming ability; soft-magnetic properties; plasticity.

\section{Introduction}

In the last two decades, the developments of BGAs have been drawing increasing attention due to many unique properties, such as high strength, superelasticity, high resistance to corrosion and good soft-magnetic properties [1-7]. Among these BGAs, Co-based BGAs exhibit excellent soft-magnetic properties and high fracture strength $\left(\sigma_{\mathrm{f}}\right)$. Nevertheless, they have not been noticed so widely as compared with the Febased BGAs because of their low GFA and low saturation magnetization $\left(I_{\mathrm{s}}\right)$. For example, $\mathrm{Co}_{43} \mathrm{Fe}_{20} \mathrm{Ta}_{5.5} \mathrm{~B}_{31.5}$ glassy alloy with a diameter of $2 \mathrm{~mm}$ developed in 2003 exhibits ultrahigh fracture strength of $5300 \mathrm{MPa}$ and extremely low coercive force $\left(H_{\mathrm{c}}\right)$ of $0.25 \mathrm{~A} \mathrm{~m}^{-1}$. However, due to the low GFA, low $I_{\mathrm{S}}$ of $0.43 \mathrm{~T}$ and poor plasticity in room temperature, almost no achievements have been addressed for the developments of the Co-based BGAs since that time [3]. Recently, some breakthrough such as high strength of 6000 MPa has been made for Co-based BGAs [8-13]. And yet, it is still a big challenge to obtain the high GFA, excellent softmagnetic properties and good plasticity at the same time for Co-based BGAs.

It has been reported that minor alloying additions are very effective in the formation of BGAs [14,15]. The minor alloying addition of Mo atoms has also been found effective in improving the GFA and plasticity of Fe-based glassy alloy system [16-25]. Recently, CoFeBSiNb glassy alloys have received widespread attention due to excellent soft magnetic

*Author for correspondence (shj@ zjnu.cn) property [26-29]. However, the problem about brittleness of the Co-based soft magnetic BGAs has not been resolved yet. The aim of this paper is to investigate the effect of Mo addition on the GFA, soft magnetic and mechanical properties of $\mathrm{CoFeBSiNb}$ glassy alloys.

\section{Experimental}

Alloy ingots with nominal compositions of $\left(\mathrm{Co}_{0.6} \mathrm{Fe}_{0.4}\right)_{69}$ $\mathrm{B}_{20.8} \mathrm{Si}_{5.2} \mathrm{Nb}_{5-x} \mathrm{Mo}_{x}(x=0,1,2,3)($ at $\%)$ were made by alloying high-purity elements in an arc furnace under an argon atmosphere. Ribbons with thickness of $20 \mu \mathrm{m}$ and width of $0.8 \mathrm{~mm}$ were prepared by the single copper roller melt-spinning method. Cylindrical alloy rods with diameters of 1-6 mm were produced by copper mould casting. The structure was examined by X-ray diffraction (XRD) with $\mathrm{CuK} \alpha$ radiation. Thermal stability associated with glass transition temperature $\left(T_{\mathrm{g}}\right)$, crystallization temperature $\left(T_{\mathrm{x}}\right)$ and supercooled liquid region $\left(\Delta T_{\mathrm{x}}=T_{\mathrm{x}}-T_{\mathrm{g}}\right)$ was examined by differential scanning calorimetry (DSC) at a heating rate of $0.67 \mathrm{~K} \mathrm{~s}^{-1}$. Compressive test was performed on an Instron testing machine at a strain rate of $5 \times 10^{-4} \mathrm{~s}^{-1}$ at room temperature using the glassy rods with a dimension of $2 \mathrm{~mm}$ in diameter and $4 \mathrm{~mm}$ in length. $I_{\mathrm{s}}$ was measured with a vibrating sample magnetometer (VSM) under an applied field of $400 \mathrm{kA} \mathrm{m}^{-1}$. $H_{\mathrm{c}}$ was measured with a B-H loop tracer under a field of $800 \mathrm{~A} \mathrm{~m}^{-1} . \mu_{\mathrm{e}}$ from 1 to $100 \mathrm{kHz}$ was measured with an impedance analyzer under a field of $1 \mathrm{~A} \mathrm{~m}^{-1}$. As the magnetic properties are affected with the sample sizes, 
to clarify the intrinsic soft-magnetic properties of this Cobased glassy alloy system, ribbon samples with the same size as mentioned above were used for measurement. All the samples for magnetic property measurements were annealed for $300 \mathrm{~s}$ at the temperature of $T_{\mathrm{g}}=50 \mathrm{~K}$ for improving soft-magnetic properties through structural relaxation.

\section{Results and discussion}

DSC curves of the melt-spun $\left(\mathrm{Co}_{0.6} \mathrm{Fe}_{0.4}\right)_{69} \mathrm{~B}_{20.8} \mathrm{Si}_{5.2} \mathrm{Nb}_{5-x}$ $\operatorname{Mo}_{x}(x=0,1,2,3)($ at $\%)$ glassy alloy ribbons are shown in figure 1. It is seen that all the alloys exhibit distinct glass transition, followed by a supercooled liquid region, and then crystallization. Although $T_{\mathrm{g}}$ and $T_{\mathrm{x}}$ decrease gradually from 845 to $830 \mathrm{~K}$ and from 905 to $890 \mathrm{~K}$, respectively, $\Delta T_{\mathrm{x}}$ maintains a nearly constant value of about $60 \mathrm{~K}$. Figure 2 shows XRD patterns of the $\left(\mathrm{Co}_{0.6} \mathrm{Fe}_{0.4}\right)_{69} \mathrm{~B}_{20.8} \mathrm{Si}_{5.2} \mathrm{Nb}_{4} \mathrm{Mo}_{1}$ glassy alloy subjected to annealing for $1200 \mathrm{~s}$ at $881 \mathrm{~K}$, which is between $T_{\mathrm{g}}$ and $T_{\mathrm{x}}$, and $600 \mathrm{~s}$ at 975 and $1193 \mathrm{~K}$, corresponding to the temperatures just above the main and the second exothermic peaks, respectively. The XRD pattern of the asspun glassy alloy is also shown for comparison. The XRD patterns are identified as a complex face-centered-cubic (Co, $\mathrm{Fe})_{23} \mathrm{~B}_{6}$ phase for the sample annealed at $881 \mathrm{~K}$. The precipitations for the sample annealed at $975 \mathrm{~K}$ corresponding to the temperature above the first exothermic peak are a mixture of $(\mathrm{Co}, \mathrm{Fe})_{23} \mathrm{~B}_{6}$ and fcc- $(\mathrm{Co}, \mathrm{Fe})$ phases. We also confirmed that the structure after annealing for $600 \mathrm{~s}$ at $1193 \mathrm{~K}$, corresponding to the second exothermic peak consisted of fcc- $(\mathrm{Co}, \mathrm{Fe})$, $(\mathrm{Co}, \mathrm{Fe}) \mathrm{B},(\mathrm{Co}, \mathrm{Fe})_{2} \mathrm{~B},(\mathrm{Co}, \mathrm{Fe})_{2} \mathrm{Si}$, and $(\mathrm{Co}, \mathrm{Fe})_{3} \mathrm{Mo}_{2} \mathrm{Si}$ phases. Therefore, it is concluded that the primary precipitation phase of the $(\mathrm{Co}, \mathrm{Fe})_{23} \mathrm{~B}_{6}$ is in a metastable state. It has been pointed out by Imafuku et al [30] that the essential structural feature in $\mathrm{Fe}-\mathrm{Nb}-\mathrm{B}$ glassy alloys is the distorted dense random network of trigonal prisms connected

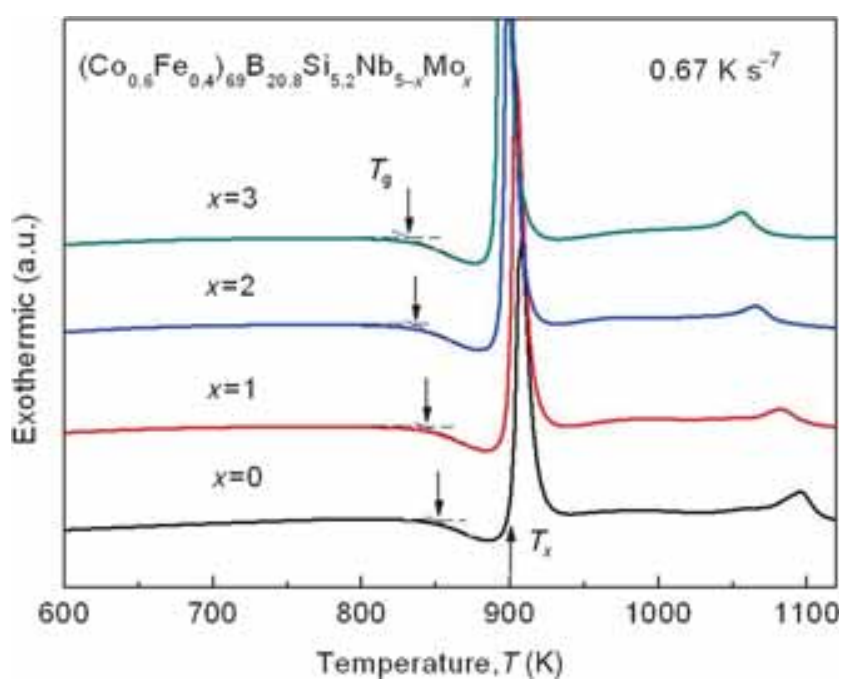

Figure 1. DSC curves of melt-spun CoFeBSiNbMo glassy alloy ribbons. with each other through glue atoms of $\mathrm{Nb}$, which leads to the high stability of supercooled liquid against crystallization.

We also investigated the melting behaviour of the $\left(\mathrm{Co}_{0.6} \mathrm{Fe}_{0.4}\right)_{69} \mathrm{~B}_{20.8} \mathrm{Si}_{5.2} \mathrm{Nb}_{5-x} \mathrm{Mo}_{x}(x=0,1,2,3)($ at\%) alloy system. As shown in figure 3 , for the 0 at $\%$ Mo-containing alloy, three endothermic peaks marked as $P_{\text {endo1 }}, P_{\text {endo2 }}$ and $P_{\text {endo3 }}$ are seen, which implies that the composition is far from the eutectic point. By adding 1 at $\%$ Mo, the $P_{\text {endo } 1}$ peak disappears completely, and the peak $P_{\text {endo3 }}$ becomes weak, implying that the composition of the alloy approaches a eutectic point with increasing Mo content. Therefore, it is considered that except for the high thermal stability of the supercooled liquid, the $\left(\mathrm{Co}_{0.6} \mathrm{Fe}_{0.4}\right)_{69} \mathrm{~B}_{20.8} \mathrm{Si}_{5.2} \mathrm{Nb}_{4} \mathrm{Mo}_{1}$ alloy

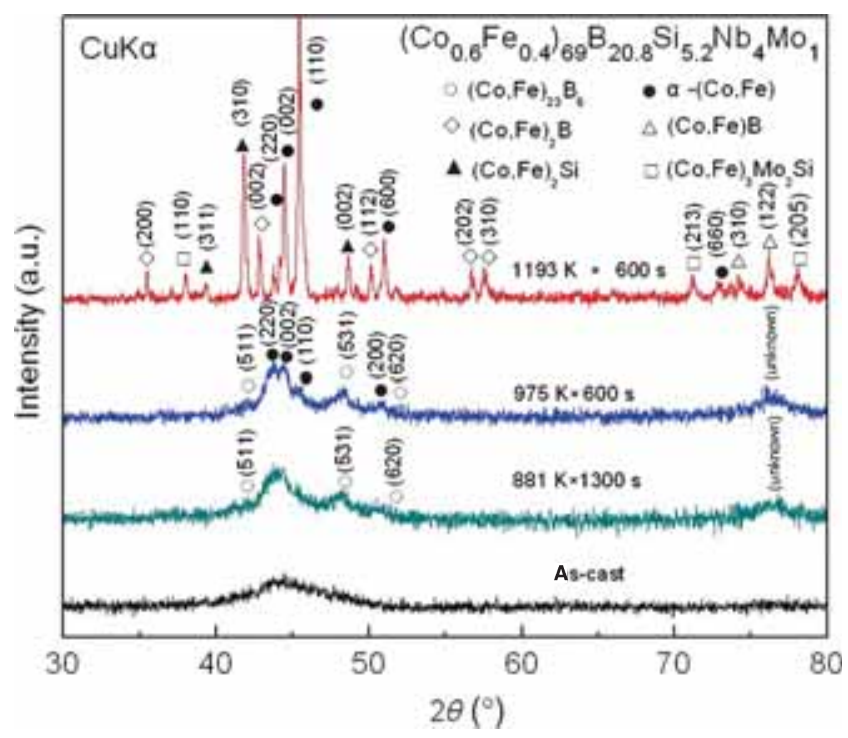

Figure 2. XRD patterns of the $\left(\mathrm{Co}_{0.6} \mathrm{Fe}_{0.4}\right)_{69} \mathrm{~B}_{20.8} \mathrm{Si}_{5.2} \mathrm{Nb}_{4} \mathrm{Mo}_{1}$ glassy alloy as-cast and annealed samples.

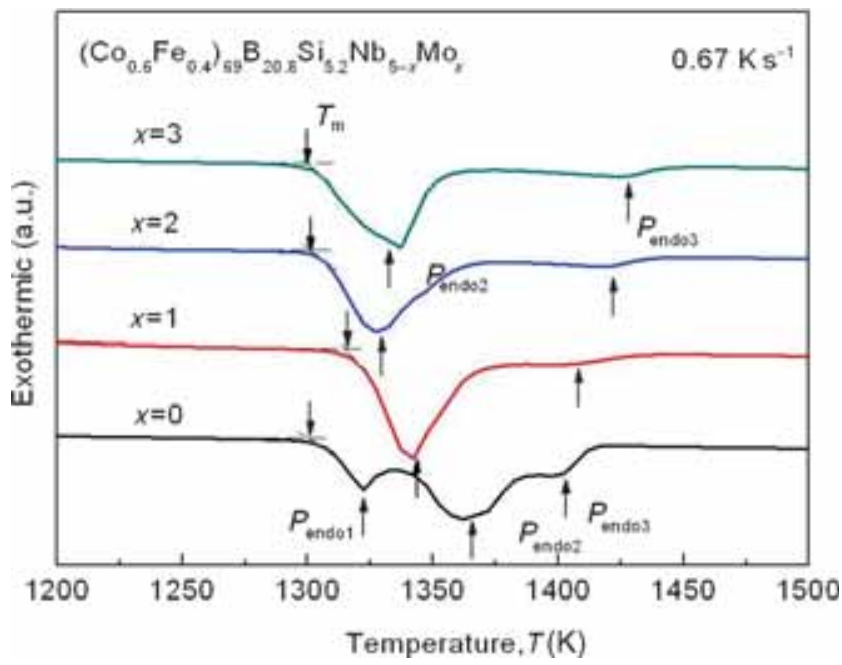

Figure 3. DSC curves of $\left(\mathrm{Co}_{0.6} \mathrm{Fe}_{0.4}\right)_{69} \mathrm{~B}_{20.8} \mathrm{Si}_{5.2} \mathrm{Nb}_{5-x} \mathrm{Mo}_{x}$ $(x=0,1,2,3)$ alloys. 
Table 1. Maximum diameter, thermal stability, mechanical and magnetic properties of cast $\left(\mathrm{Co}_{0.6} \mathrm{Fe}_{0.4}\right)_{69} \mathrm{~B}_{20.8} \mathrm{Si}_{5.2} \mathrm{Nb}_{5-x} \mathrm{Mo}_{x}(x=0$, $1,2,3)$ glassy alloy rods.

\begin{tabular}{|c|c|c|c|c|c|c|c|c|c|c|c|}
\hline \multirow[b]{2}{*}{ Alloy } & \multirow{2}{*}{$\begin{array}{l}D_{\max } \\
(\mathrm{mm})\end{array}$} & \multicolumn{4}{|c|}{ Thermal stability } & \multicolumn{3}{|c|}{ Mechanical properties } & \multicolumn{3}{|c|}{ Magnetic properties } \\
\hline & & $T_{\mathrm{g}}(\mathrm{K})$ & $T_{\mathrm{X}}(\mathrm{K})$ & $\Delta T_{\mathrm{X}}(\mathrm{K})$ & $T_{\mathrm{m}}(\mathrm{K})$ & $E(\mathrm{GPa})$ & $\sigma_{\mathrm{f}}(\mathrm{MPa})$ & $\varepsilon_{\mathrm{p}}(\%)$ & $I_{\mathrm{S}}(\mathrm{T})$ & $H_{\mathrm{c}}\left(\mathrm{A} \mathrm{m}^{-1}\right)$ & $\mu_{\mathrm{e}}(1 \mathrm{kHz})$ \\
\hline$\left(\mathrm{Co}_{0.6} \mathrm{Fe}_{0.4}\right)_{69} \mathrm{~B}_{20.8} \mathrm{Si}_{5.2} \mathrm{Nb}_{5}$ & 4 & 845 & 905 & 60 & 1307 & 208 & 4160 & 0.1 & 0.87 & 1.0 & 18600 \\
\hline$\left(\mathrm{Co}_{0.6} \mathrm{Fe}_{0.4}\right)_{69} \mathrm{~B}_{20.8} \mathrm{Si}_{5.2} \mathrm{Nb}_{4} \mathrm{Mo}_{1}$ & 5 & 840 & 900 & 60 & 1322 & 210 & 4210 & 0.4 & 0.86 & 0.7 & 24100 \\
\hline$\left(\mathrm{Co}_{0.6} \mathrm{Fe}_{0.4}\right)_{69} \mathrm{~B}_{20.8} \mathrm{Si}_{5.2} \mathrm{Nb}_{3} \mathrm{Mo}_{2}$ & 4.5 & 835 & 895 & 60 & 1306 & 210 & 4190 & 0.8 & 0.85 & 0.8 & 20400 \\
\hline$\left(\mathrm{Co}_{0.6} \mathrm{Fe}_{0.4}\right)_{69} \mathrm{~B}_{20.8} \mathrm{Si}_{5.2} \mathrm{Nb}_{2} \mathrm{Mo}_{3}$ & 4 & 830 & 890 & 60 & 1303 & 210 & 4190 & 1.0 & 0.84 & 1.0 & 19000 \\
\hline
\end{tabular}

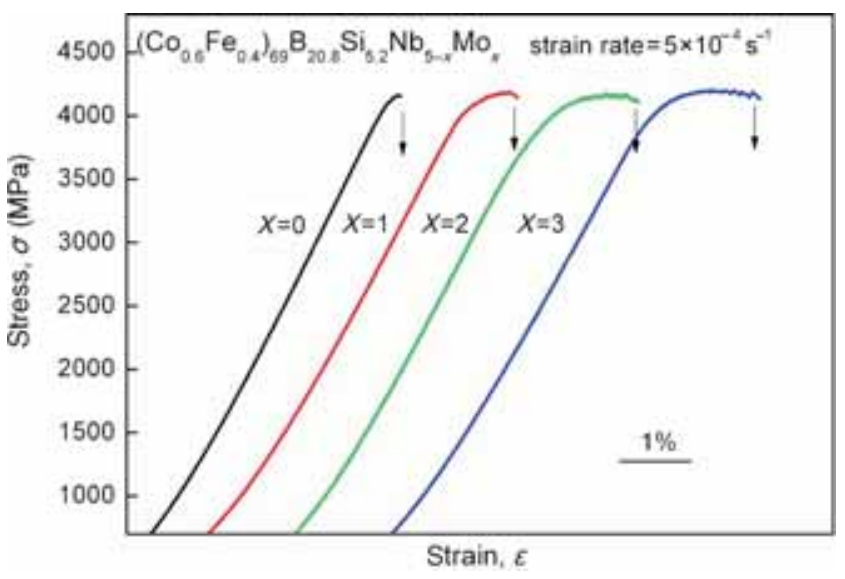

Figure 4. Compressive stress-strain curves of CoFeBSiNbMo glassy alloy rods with a diameter of $2 \mathrm{~mm}$.

lies in the vicinity of a eutectic point. This result indicates that higher glass-forming ability may be obtained by adding Mo content. However, with further increasing Mo content to $2-3$ at $\%$, as can be seen from figure 3, the temperature interval between $P_{\text {endo2 }}$ and $P_{\text {endo3 }}$ increases, which implies that the composition deviate from the eutectic point again. Based on the results obtained from DSC measurements, it is expected that this alloy system, especially for the alloy with Mo contents of $x=1$, exhibits a high GFA. We tried to form cylindrical glassy rods with different diameters up to $6 \mathrm{~mm}$. The critical diameters of glassy alloy rods were $4,5,4.5$ and $4 \mathrm{~mm}$ for the alloys with Mo contents of $x=0,1,2$ and 3, respectively.

Table 1 summarizes the maximum diameter, thermal stability, mechanical and magnetic properties of the $\left(\mathrm{Co}_{0.6} \mathrm{Fe}_{0.4}\right)_{69}$ $\mathrm{B}_{20.8} \mathrm{Si}_{5.2} \mathrm{Nb}_{5-x} \mathrm{Mo}_{x}(x=0,1,2,3)$ (at\%) glassy alloys. In addition to high GFA, superhigh strength and good plasticity, this BGA system also exhibits excellent soft-magnetic properties, i.e., high $I_{\mathrm{s}}$ of $0.84-0.87 \mathrm{~T}$, extremely low $H_{\mathrm{c}}$ of $0.7-1.0 \mathrm{~A} \mathrm{~m}^{-1}$, high $\mu_{\mathrm{e}}$ of $(1.86-2.41) \times 10^{4}$. It is therefore concluded that this $\left(\mathrm{Co}_{0.6} \mathrm{Fe}_{0.4}\right)_{69} \mathrm{~B}_{20.8} \mathrm{Si}_{5.2} \mathrm{Nb}_{5-x} \mathrm{Mo}_{x}$ ferromagnetic BGA system simultaneously possesses high GFA, superhigh $\sigma_{\mathrm{f}}$, good $\varepsilon_{\mathrm{p}}$, high $I_{\mathrm{s}}$, low $H_{\mathrm{c}}$ and high $\mu_{\mathrm{e}}$.

Figure 4 presents the true compressive strain-stress curves for the $\left(\mathrm{Co}_{0.6} \mathrm{Fe}_{0.4}\right)_{69} \mathrm{~B}_{20.8} \mathrm{Si}_{5.2} \mathrm{Nb}_{5-x} \mathrm{Mo}_{x}$ alloy rods specimens with a diameter of $2 \mathrm{~mm}$ and a length of $4 \mathrm{~mm}$. The fracture strength $\sigma_{\mathrm{f}}$ and the plastic strain $\varepsilon_{\mathrm{p}}$ of the specimens are listed in table 1. With the increment of Mo content, the yield strength and compressive strength remained almost unchanged, whereas the plastic strain increases gradually. The $\left(\mathrm{Co}_{0.6} \mathrm{Fe}_{0.4}\right)_{69} \mathrm{~B}_{20.8} \mathrm{Si}_{5.2} \mathrm{Nb}_{5-x} \mathrm{Mo}_{x}$ BGAs exhibit ultrahigh $\sigma_{\mathrm{f}}$ $(4160-4260 \mathrm{MPa})$ and good $\varepsilon_{\mathrm{p}}(0.1-1.0 \%)$. Figure 5 shows the surface SEM images of the $\left(\mathrm{Co}_{0.6} \mathrm{Fe}_{0.4}\right)_{69} \mathrm{~B}_{20.8} \mathrm{Si}_{5.2} \mathrm{Nb}_{2}$ $\mathrm{Mo}_{3}$ specimen after compression loading prior to failure. Localized main shear band forms from the top surface and ends up at the sample side, which is characterized by a shear angle of about 50 and $32^{\circ}$ to the compressive axis (see figure 5a). As can be seen in figure $5 \mathrm{~b}$, enlarged region exhibits an obvious shear-deformation-induced slip in the compressive sample. Around the existing primary shear band, it is noted that several remarkable cracks and scattered shear bands are present. The formation of such cracks without instable propagation gives us a hint that the BGA holds a definite resistance to catastrophic failure of brittle materials. Figure $5 \mathrm{c}$ shows another lateral morphology of the cylindrical sample. The secondary shear bands developed by branching and interaction of the primary ones and perpendicular to the main shear planes, which are responsible for the significant plastic deformation.

After fracture, the sample splits into pieces of small fragments as shown in figure 6 , similar to other brittle Feand Co-based BGAs [31-34]. The fracture surface of the $\left(\mathrm{Co}_{0.6} \mathrm{Fe}_{0.4}\right)_{69} \mathrm{~B}_{20.8} \mathrm{Si}_{5.2} \mathrm{Nb}_{2} \mathrm{Mo}_{3}$ alloy exhibits mixed feature composed of shell-like and vein-like patterns. Vein patterns often reflect the local viscous flow of amorphous metals and only occur in those BGAs with good plasticity such as $\mathrm{Fe}_{71} \mathrm{Nb}_{6} \mathrm{~B}_{23}$ metallic glass [35]. Thus, the appearance of the vein-like patterns in the fragments evidently verifies its enhanced plasticity. They are rarely observed in the extremely brittle Co-based BGAs, instead in shell-like or mirror-like surfaces at microscale due to a catastrophic fracture. The Mo doping $\left(\mathrm{Co}_{0.6} \mathrm{Fe}_{0.4}\right)_{69} \mathrm{~B}_{20.8} \mathrm{Si}_{5.2} \mathrm{Nb}_{5-x} \mathrm{Mo}_{x}$ BGAs with good room temperature plasticity may be ascribed to the following reasons. Firstly, Mo has a low shear modulus $G(20 \mathrm{GPa}$ ) and $G / K$ ( $K$ is bulk modulus) value (0.09), which may result in a large plastic strain [36]. Secondly, the deformation-induced microstructural change could take place easily in the metallic glass with the low glass transition temperature $T_{\mathrm{g}}$ in the process of mechanical deformation. Furthermore, it has been reported that $T_{\mathrm{g}}$ is 

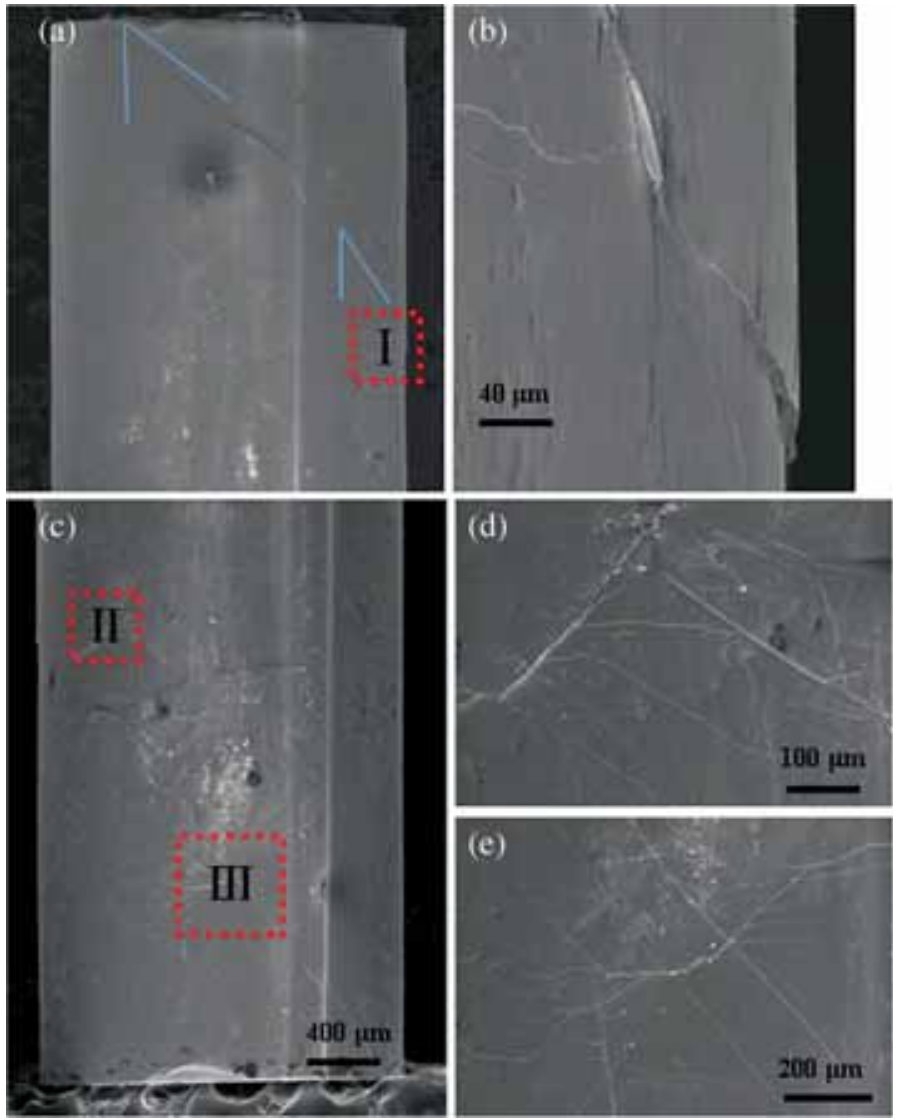

Figure 5. SEM images of the $\left(\mathrm{Co}_{0.6} \mathrm{Fe}_{0.4}\right)_{69} \mathrm{~B}_{20.8} \mathrm{Si}_{5.2} \mathrm{Nb}_{2} \mathrm{Mo}_{3}$ specimen after compression loading prior to failure. (a, c) Lateral morphology of the deformed surface and (b, $\mathbf{d}$ and $\mathbf{e}$ ) high magnification SEM images corresponding to the zone marked by the rectangle in I-III, respectively.
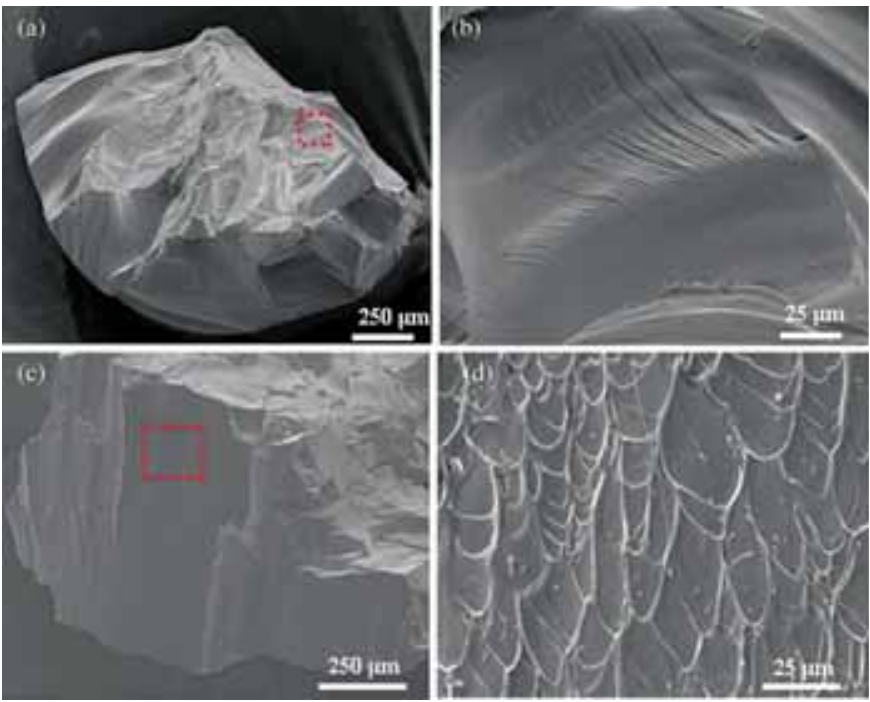

Figure 6. (a, c) SEM images of the fracture surface of $\left(\mathrm{Co}_{0.6} \mathrm{Fe}_{0.4}\right)_{69} \mathrm{~B}_{20.8} \mathrm{Si}_{5.2} \mathrm{Nb}_{2} \mathrm{Mo}_{3}$ alloy. (b, d) High magnification SEM images corresponding to the zone marked by the rectangle in a and $\mathbf{c}$, respectively. 
closely related to the shear modulus, which affects significantly the plasticity of BGAs $[37,38]$. For the current Mo doping $\left(\mathrm{Co}_{0.6} \mathrm{Fe}_{0.4}\right)_{69} \mathrm{~B}_{20.8} \mathrm{Si}_{5.2} \mathrm{Nb}_{5-x} \mathrm{Mo}_{x}$ BGAs, as shown in table 1 , the $T_{\mathrm{g}}$ of the alloy with Mo doping decreases from 845 to $830 \mathrm{~K}$, reflecting the decrease in shear modulus. This means that the shear deformation and the forming of nanocrystals or nanoclusters could easily occur in the Mo doping BGAs. Besides, the activation barrier for viscous flow is proportional to shear modulus. And the viscous flow also correlate with the plastic deformation of BGAs [39].

\section{Conclusion}

In conclusion, $\left(\mathrm{Co}_{0.6} \mathrm{Fe}_{0.4}\right)_{69} \mathrm{~B}_{20.8} \mathrm{Si}_{5.2} \mathrm{Nb}_{5-x} \mathrm{Mo}_{x}$ ferromagnetic BGA cylindrical glassy rods were successfully fabricated with a diameter of $5 \mathrm{~mm}$ by conventional copper mould casting method. It reveals that the substitution of a small amount of $\mathrm{Mo}$ for $\mathrm{Nb}$ make the composition to approach a eutectic point and effectively enhance the GFA of alloy. In addition to high GFA and superhigh strength, the compressive test shows that the Mo addition can improve the plasticity for the present $\left(\mathrm{Co}_{0.6} \mathrm{Fe}_{0.4}\right)_{69} \mathrm{~B}_{20.8} \mathrm{Si}_{5.2} \mathrm{Nb}_{5-x} \mathrm{Mo}_{x}$ BGAs. Among, $\left(\mathrm{Co}_{0.6} \mathrm{Fe}_{0.4}\right)_{69} \mathrm{~B}_{20.8} \mathrm{Si}_{5.2} \mathrm{Nb}_{2} \mathrm{Mo}_{3} \mathrm{BGA}$ has the high fracture strength of $4190 \mathrm{MPa}$ and the good plastic strain of $1 \%$. Besides, this BGA system also exhibits excellent soft-magnetic properties with high $I_{\mathrm{S}}$ of 0.84 $0.87 \mathrm{~T}$, extremely low $H_{\mathrm{c}}$ of $0.7-1.0 \mathrm{~A} \mathrm{~m}^{-1}$ and high $\mu_{\mathrm{e}}$ of $(1.86-2.41) \times 10^{4}$. With the combination of high GFA, superhigh fracture strength, good plasticity, as well as high saturation magnetization and excellent soft-magnetic properties, this Co-based ferromagnetic glassy alloy system is promising for the future applications as functional materials.

\section{Acknowledgements}

This work was supported by the Nature Science Foundation of Zhejiang Province (Grant no. LQ13E010003), the Zhejiang Provincial Key Science and Technology Innovation Team (Grant no. 2011R50012), Zhejiang Provincial Key Laboratory (Grant no. 2013E10022) and National Nature Science Foundation (Grant no. 51301153).

\section{References}

[1] Greer A L 1995 Science 2671947

[2] Greer A L and Ma E 2007 MRS Bull. 32611

[3] Inoue A 2003 Nat. Mater. 2661

[4] Xu D H, Duan G and Johnson W L 2004 Phys. Rev. Lett. 92 245504

[5] Ponnambalam V, Poon S J and Shiflet G J 2004 J. Mater. Res. 191320

[6] Zhang B, Zhao D Q, Pan M X, Wang W H and Greer A L 2005 Phys. Rev. Lett. 94205502
[7] Lu Z P, Liu C T, Thompson J R and Porter W D 2004 Phys. Rev. Lett. 92245503

[8] Wang J F, Li R, Hua N B and Zhang T 2011 J. Mater. Res. 26 2072

[9] Men H, Pang S J and Zhang T 2007 Mater. Sci. Eng. A 449451538

[10] Fan J T, Zhang Z F, Shen B L and Mao S X 2009 Intermetallics 17445

[11] Dun C C, Liu H S and Shen B L 2012 J. Non-Cryst. Solids 3583060

[12] Zhu C L, Wang Q, Wang Y M, Qiang J B and Dong C 2010 J. Alloys Compd. 504 S34

[13] Sun H J, Li L and Shen B L 2012 J. Non-Cryst. Solids 358911

[14] Lu Z P and Liu C T 2004 J. Mater. Sci. 393965

[15] Wang W H 2007 Prog. Mater. Sci. 52540

[16] Yang X H, Ma X H, Li Q and Guo S F 2013 J. Alloys Compd. $\mathbf{5 5 4} 446$

[17] Li X, Qin C L, Makino A and Inoue A 2011 J. Alloys Compd. 5097688

[18] Zhang W, Fang C F and Li Y H 2013 Scripta Mater. 6977

[19] Liu F J, Pang S J, Li R and Zhang T 2009 J. Alloys Compd. 483613

[20] Gu X J, Poon J, Shiflet G J and Widom M 2008 Appl. Phys. Lett. 92161910

[21] Li H X, Kim K B and Yi S 2007 Scripta Mater. 561035

[22] Huang X M, Wang X D, Cao Q P and Jiang J Z 2009 Scripta Mater. 60152

[23] Li F S, Shen B L, Makino A and Inoue A 2007 Appl. Phys. Lett. 91234101

[24] Bhattacharya S, Poon S J and Shiflet G J 2009 J. Alloys Compd. 48879

[25] Demetriou M D, Lass E A, Schramm J P and Johnson W L 2009 Appl. Phys. Lett. 95041907

[26] Chang C T, Shen B L and Inoue A 2006 Appl. Phys. Lett. 100 011901

[27] Shen B L, Zhou Y J, Chang C T and Inoue A 2007 J. Appl. Phys. 101 09N101

[28] Sun H J, Shen B L and Inoue A 2010 J. Appl. Phys. 107 09A319

[29] Sun H J, Shen B L and Inoue A 2010 J. Alloys Compd. 504 S31

[30] Imafuku M, Sato S, Kosiba H and Inoue A 2000 Mater. Trans. JIM 411526

[31] Inoue A, Shen B L, Yavari A R and Greer A L 2003 J. Mater. Res. 181487

[32] Stoica M, Eckert J, Roth S, Zhang Z F, Schultz L and Wang W H 2005 Intermetallics 13764

[33] Zhang Z F, Zhang H, Shen B L, Inoue A and Eckert J 2006 Philos. Mag. Lett. 86643

[34] Fan J T, Zhang Z F, Mao S X, Shen B L and Inoue A 2009 Intermetallics 17445

[35] Yao J H, Wang J Q and Li Y 2008 Appl. Phys. Lett. 92251906

[36] Gu X J, Poon S J, Shiflet G J and Widom M 2008 Acta Mater. 5688

[37] Johnson W L and Samwer K 2005 Phys. Rev. Lett. 95195501

[38] Zhang L, Shi L L and Xu J 2009 J. Non-Cryst. Solid 3551005

[39] Dyre J C 2006 Rev. Mod. Phys. 78953 